\title{
Pembelajaran Keterampilan Menulis (Maharah al-Kitabah) dalam Bahasa Arab
}

\author{
Munawarah $^{1}$, Zulkiflih $^{2}$ \\ ${ }^{1,2}$ Institut Agama Islam DDI Polewali Mandar, Sulawesi Barat \\ 1e-mail: munawarah@ddipolman.ac.id \\ 2e-mail: zulkiflih@ddipolman.ac.id
}

\begin{abstract}
Writing skill (maharah al-kitabah) is the highest skill of the four language skills. Writing is an activity that has a relationship with thought processes and expression skills in the form of writing. Judging from the aspect of Arabic proficiency, writing can be said to be a very complex activity, because it requires the ability to organize and organize ideas coherently and logically, as well as the ability to present writing in a variety of written languages and different writing rules. This writing activity is difficult for students, because it requires several skills, namely skills in forming letters and mastering spelling and the skills to generate thoughts and feelings in the form of Arabic writing. Therefore, it is necessary to understand the objectives and principles of learning writing skills and writing skills learning techniques to help students understand the material and achieve the goals of learning writing skills (Maharah al-kitabah). This paper tries to explain the theory of learning writing skills scientifically which includes the understanding of writing skills (maharah al-kitabah), the objectives of learning writing skills (maharah al-kitabah), the principles of learning writing skills (maharah al-kitabah) and skills learning techniques. write (maharah al-kitabah) in Arabic.
\end{abstract}

Keywords: Learning techniques, learning writing skills, Arabic learning.

\begin{abstract}
Abstrak
Keterampilan menulis (maharah al-kitabah) adalah suatu keterampilan tertinggi dari empat keterampilan berbahasa. Menulis merupakan kegiatan yang memiliki hubungan dengan proses berpikir serta keterampilan ekspresi dalam bentuk tulisan. Dilihat dari aspek kemahiran berbahasa Arab, menulis dapat dikatakan sebagai suatu kegiatan yang sangat kompleks, sebab menuntut suatu kemampuan untuk menata dan mengorganisasikan ide secara runtut dan logis, serta kemampuan dalam hal menyajikan tulisan dalam ragam bahasa tulis dan kaidah penulisan yang berbeda-beda. Aktifitas menulis ini adalah hal yang sulit bagi siswa, karena membutuhkan beberapa keterampilan, yaitu keterampilan dalam membentuk huruf serta menguasai ejaan dan keterampilan melahirkan pikiran dan perasaan dalam bentuk tulisan berbahasa Arab. Oleh sebab itu, perlunya dipahami tujuan dan prinsip pembelajaran keterampilan menulis serta teknik pembelajaran keterampilan menulis untuk membantu siswa dalam memahami materi dan mencapai tujuan pembelajaran keterampilan menulis (maharah al-kitabah). Tulisan ini mencoba memaparkan teori pembelajaran keterampilan menulis secara ilmiah yang meliputi pengertian keterampilan menulis (maharah al-kitabah), tujuan pembelajaran keterampilan menulis (maharah al-kitabah), prinsip-prinsip dalam pembelajaran keterampilan menulis (maharah al-kitabah) dan teknik pembelajaran keterampilan menulis (maharah al-kitabah) dalam bahasa Arab.
\end{abstract}

Kata Kunci: Teknik pembelajaran, katerampilan menulis, pembelajaran bahasa Arab 


\section{Loghat Arabi: Jurnal Bahasa Arab \& Pendidikan Bahasa Arab}

\section{Pendahuluan}

Kemahiran berbahasa secara umumnya terbagi pada empat bagian yaitu; maharah alistima', maharah al-kalam, maharah al-qira'ah, dan maharah al-kitabah. Keempat keterampilan berbahasa ini tentu harus saling melengkapi, mempengaruhi dan dipengaruhi. Pengalaman dan masukan yang diperoleh dari menyimak, berbicara, dan membaca, akan memberikan kontribusi berharga dalam menulis, begitu pula sebaliknya. Namun demikian, menulis memiliki karakter khas yang membedakannya dari yang lainnya. Sifat aktif dan produktif dalam menulis memberikannya ciri khusus dalam hal kecaraan, medium, dan ragam bahasa yang digunakannya.

Keterampilan menulis (maharah al-kitabah) merupakan keterampilan tertinggi dari empat keterampilan berbahasa. Menulis merupakan kegiatan yang mempunyai hubungan dengan proses berpikir serta keterampilan ekspresi dalam bentuk tulisan. Menulis dapat dikatakan sebagai suatu kegiatan yang sangat kompleks, sebab terletak pada tuntutan kemampuan untuk menata dan mengorganisasikan ide secara runtut dan logis, serta kemampuan dalam konteks menyajikan tulisan dalam ragam bahasa tulis dan kaidah penulisan yang berbeda-beda.

Dalam hal ini Syamsuddin Asyrofi menyatakan, setidaknya ada dua aspek yang ada dalam kegiatan menulis, yaitu kemahiran dalam membentuk huruf dan menguasai ejaan dan kemahiran melahirkan pikiran dan perasaan dalam bentuk tulisan berbahasa Arab. ${ }^{1}$ Artinya, dibalik kerumitannya, kemahiran menulis memiliki manfaat besar sebagai pendukung penting dalam kegiatan berbahasa, khususnya kontribusinya dalam membantu pengembangan daya inisiatif dan kreativitas anak-anak untuk menemukan, mengumpulkan, mengolah dan menata informasi yang kemudian tersajikan dalam bentuk tulisan bermutu. Menulis (kitabah) adalah pekerjaan yang sulit bagi anak-anak dan memerlukan beberapa keterampilan. Dalam hal ini kesalahan-kesalahan pasti terjadi, namun hal inilah yang akan membawa mereka pada tingkatan yang lebih tinggi lagi dalam keterampilan menulis (maharah al-kitabah). Urutan pembelajaran bahasa yang sebenarnya adalah dimulai dari menyimak (istima'), berbicara (kalam), membaca (qira'ah), dan yang terakhir adalah menulis (kitabah). Pada tingkat pemula tidak menekankan pengajaran pada pengetahuan bahasa, tetapi lebih menekankan pada kemampuan berbahasa, baik lisan maupun tulisan.

\footnotetext{
${ }^{1}$ Syamsuddin Asyrofi, Metodologi Pembelajaran Bahasa Arab (Yogyakarta: Idea Press, 2010), h. 135.
} 


\section{Loghat Arabi: Jurnal Bahasa Arab \& Pendidikan Bahasa Arab}

Dilihat dari aspek kemahiran berbahasa Arab, menulis dapat dikatakan sebagai suatu kegiatan yang sangat kompleks, sebab menuntut suatu kemampuan untuk menata dan mengorganisasikan ide secara runtut dan logis, serta kemampuan dalam hal menyajikan tulisan dalam ragam bahasa tulis dan kaidah penulisan yang berbeda-beda. Aktifitas menulis ini adalah hal yang sulit bagi siswa, karena membutuhkan beberapa keterampilan, yaitu keterampilan dalam membentuk huruf serta menguasai ejaan dan keterampilan melahirkan pikiran dan perasaan dalam bentuk tulisan berbahasa Arab. Oleh sebab itu, perlunya dipahami tujuan dan prinsip pembelajaran keterampilan menulis serta teknik pembelajaran keterampilan menulis untuk membantu siswa dalam memahami materi dan mencapai tujuan pembelajaran keterampilan menulis (maharah al-kitabah). Tulisan ini mencoba memaparkan teori pembelajaran keterampilan menulis secara ilmiah yang meliputi pengertian keterampilan menulis (maharah al-kitabah), tujuan pembelajaran keterampilan menulis (maharah alkitabah), prinsip-prinsip dalam pembelajaran keterampilan menulis (maharah al-kitabah) dan teknik pembelajaran keterampilan menulis (maharah al-kitabah) dalam bahasa Arab.

Secara metodologis, tulisan ini bersifat deskriptif kualitatif karena hanya mengolah data pusataka berupa tulisan dan pernyataan yang sesuai dengan tema yang dibahas kemudian dideskripsikan berdasarkan permasalahan yang dikaji, dan pada bagian terakhir disimpulkan.

\section{Pengertian Maharah al-Kitabah (Keterampilan Menulis)}

Kitabah menurut bahasa adalah kumpulan kata yang tersusun dan teratur. Adapun makna kitabah secara epistimologi adalah kumpulan dari kata yang tersusun dan mengandung arti, karena kitabah tidak akan terbentuk kecuali dengan adanya kata yang beraturan. Dan dengan adanya kitabah manusia bisa menuangkan expresi hatinya dengan bebas sesuai dengan apa yang difikirkannya. Dengan menuangkan ungkapan yang tertulis diharapkan para pembaca dapat mengerti apa yang ingin penulis ungkapkan. ${ }^{2}$

Keterampilan menulis (maharah al-kitabah/ writing skill) adalah kemampuan dalam mendeskripsikan atau mengungkapkan isi pikiran, mulai dari aspek yang sederhana seperti menulis kata-kata sampai kepada aspek yang kompleks yaitu mengarang. ${ }^{3}$

Aspek-aspek dalam maharah al-kitabah menurut 'Ulyan adalah al-qawaid (nahwu dan sharf), imla' dan khat. Adapun unsur-unsur dalam kitabah adalah al-kalimah (satuan kata

${ }^{2}$ Ahmad Fuad Mahmud 'Ulyan, al-Maharah al-Lughawiyah, Mahiyatuha wa Turuqu Tadrisuha (Riyadh: Darul Muslim, 1992), h. 156. 51.

${ }^{3}$ Acep Hermawan, Metodologi Pembelajaran Bahasa Arab (Bandung: Remaja Rosdakarya, 2011), h. 
yang terkecil dari satuan kalimat atau unsur dasar pembentukan kalimat), al-jumlah (kumpulan kata yang dapat membentuk pemahaman makna atau satu kata yang disandarkan dengan kata yang lain), al-fakrah (paragraf) dan $u s l u b .^{4}$

Abdul Hamid mengemukakan bahwa kemahiran menulis mempunyai tiga aspek, yaitu sebagai berikut:

1. Kemahiran membentuk huruf dan penguasaan ejaan;

2. Kemahiran memperbaiki khoth;

3. Kemahiran melahirkan fikiran dan perasaan dengan tulisan. ${ }^{5}$

Pada dasarnya, kitabah merupakan suatu kegiatan yang produktif dan ekspresif. Dalam kegiatan kitabah, seorang menulis harus terampil memanfaatkan grafologi, struktur bahasa, dan kosa kata. Keterampilan menulis digunakan untuk mencatat, merekam, meyakinkan, melaporkan, menginformasikan, dan mempengaruhi pembaca. Maksud dan tujuan pembelajaran itu hanya dapat dicapai dengan baik oleh para pelajar yang dapat menyusun dan merangkai jalan fikiran dan mengemukakannya secara tertulis dengan jelas, lancar, dan komunikatif. Kejelasan ini bergantung pada fikiran, organisasi, pemakaian dan pemilihan kata, dan struktur kalimat. ${ }^{6}$

Menulis merupakan kegiatan komunikasi yang dilakukan tanpa didukung oleh tekanan suara, nada, mimic, gerak-gerik, dan tanpa situasi seperti yang terjadi pada kegiatan komunikasi lisan. Dengan demikian, penulis harus pandai memanfaatkan kata-kata, ungkapan, kalimat, serta menggunakan fungtuasi untuk menyampaikan, menginformasikan, melukiskan dan menyarankan sesuatu kepada orang lain. ${ }^{7}$

Menulis yaitu sarana sebagai penyalur pemikiran, gagasan, ide, pengetahuan dan pesan yang akan disampaikan penulis. ${ }^{8}$ Menulis berarti mengemukakan pemikiran dan perasaan sendiri kepada orang lain secara tertulis.

Jadi dapat disimpulkan bahwa menulis adalah segenap kegiatan seseorang mengungkapkan pemikirannya melalui tulisan untuk dibaca dan dimengerti orang lain.

${ }^{4}$ Ahmad Fuad Mahmud 'Ulyan, al-Maharah al-Lughawiyah, Mahiyatuha wa Turuqu Tadrisuha, h. 190.

${ }_{6}^{5}$ M. Abdul Hamid, dkk, Pembelajaran Bahasa Arab (Malang: UIN Malang Press, 2008), h. 49.

${ }^{6}$ Anwar Efendi, Bahasa dan Sastra dalam Berbagai Prespektif (Jogjakarta: Tiara Wacana), h. 327.

7 Aziz Fachrurrozi dan Erta Mahyuddin, Teknik Pembelajaran Bahasa Arab (Bandung: Pustaka Cendekia Utama, 2011), h. 144-145.

${ }^{8}$ Kunandar, Langkah Mudah Penelitian Tindakan Kelas sebagai Pengembangan Profesi Guru (Jakarta : PT. Raja Grafindo Persada, 2011), h. 1. 
Pemikiran tersebut dapat berupa pengalaman, pendapat, pengetahuan, keinginan dan perasaan yang dituangkan dalam bentuk tulisan.

Keterampilan menulis adalah membuat huruf atau angka dengan pena, pensil, kapur dan lain-lain. Keterampilan menulis bahasa Arab merupakan keterampilan yang dianggap sulit dalam pembelajaran dan keterampilan ini juga membutuhkan waktu yang sangat lama untuk menempuh keterampilan tersebut. ${ }^{9}$

Menulis adalah sebuah kererampilan berbahasa yang terpadu, yang ditunjukan untuk menghasilkan sesuatu yang disebut tulisan. Sekurang-kurangnya ada tiga komponen yang tergabung dalam aktivitas menulis tersebut, yaitu: ${ }^{10}$

1. Penguasaan bahasa tulis, meliputi kosa kata, struktur, kalimat, paragraph, ejaan, fragmatig dan sebagainya.

2. Penguasaan isi karangan sesuai dengan topik yang akan ditulis.

3. Penguasaan tentang jenis-jenis tulisan, yaitu bagaimana merangkai isi tulisan dengan menggunakan bahasa tulis sehingga membentuk sebuah komposisi yang diinginkan, seperti esai, artikel, cerita pendek, buku dan sebagainya.

\section{Tujuan Pembelajaran Maharah al-Kitabah (Keterampilan Menulis)}

Tujuan pengajaran menulis bahasa Arab memungkinkan siswa belajar menurut Mahmud Kamil an-Naqah, sebagaimana berikut: ${ }^{11}$

1. Menulis huruf Arab dan memahami hubungan antara bentuk huruf dan suara.

2. Menulis kalimat Arab dengan huruf terpisah dan huruf bersambung dengan perbedaan bentuk huruf baik diawal, tengah ataupun akhir.

3. Penguasaan cara penulisan bahasa Arab dengan jelas dan benar.

4. Penguasaan menulis salinan kaligrafi atau tambalan-tambalan keduanya lebih mudah dipelajari.

5. Penguasaan/mampu menulis dari kanan ke kiri.

6. Mengetahui tanda baca dan petunjuknya dan cara penggunaannya.

7. Mengetahui prinsip imla' dan mengenal apa yang terdapat dalam bahasa Arab.

8. Menterjemahkan ide-ide dalam menulis kalimat dengan menggunakan tata bahasa Arab yang sesuai dengan kata.

${ }^{9}$ Taufik, Pembelajaran Bahasa Arab MI (Surabaya: PMN, 2011), h. 44.

${ }^{10}$ Syaiful Mustofa, Strategi Pembelajaran Bahasa Arab (Bandung: Remaja Rosdakarya, 2011), h. 181.

${ }^{11}$ Mahmud Kamil an-Naqah, Ta'lim Lughah al-Arabiyah Lin-Naatiqin bilughatin Ukhra (Makkah: Jamiah Ummul Qura, 1985), h. 235. 
9. Menterjemahkan ide-ide dalam menulis kalimat yang benar dengan menggunakan kata yang benar dalam konteks mengubah bentuk kata atau mengubah kontruksi makna (mufrad, mutsanna jama', mudzakar, muannast, idhafat, dsb)

10. Menterjemahkan ide-ide tertulis dengan menggunakan tata bahasa yang sesuai.

11. Menggunakan gaya bahasa yang sesuai untuk judul atau ide yang dinyatakan.

12. Kecepatan menulis mencerminkan dirinya dalam berbahasa yang benar,tepat, jelas dan ekspresif.

Adapun tujuan dari pembelajaran menulis menurut Hasan Syahatah adalah: ${ }^{12}$

1. Agar siswa terbiasa menulis bahasa Arab dengan benar.

2. Agar siswa mampu mendeskripsikan sesuatu yang dia lihat atau dia alami dengan cermat dan benar.

3. Agar siswa mampu mendeskripsikan sesuatu dengan cepat.

4. Melatih siswa untuk mengekspresikan ide dan pikirannya dengan bebas.

5. Melatih siswa terbiasa memilih kosa kata dan kalimat yang sesuai dengan konteks kehidupan.

6. Agar siswa terbiasa berfikir dan mengekspresikannya dalam tulisan dengan tepat.

7. Melatih siswa mengekspresikan ide, pikiran, gagasan dan perasaannya dalam ungkapan bahasa Arab yang benar, jelas, berkesan dan imajinatif.

8. Agar siswa cermat dalam menulis teks Arab dalam berbagai kondisi.

9. Agar pikiran siswa semakin luas dan mendalam serta terbiasa berpikir logis dan sistematis.

Kemudian terdapat tujuan pembelajaran keterampilan menulis berdasarkan tingkatannya:

1. Tingkat pemula

a. Menyalin satuan-satuan bahasa yang sederhana

b. Menulis satuan bahasa yang sederhana

c. Menulis pernyataan dan pertanyaan yang sederhana

d. Menulis paragraf pendek

2. Tingkat menengah

a. Menulis pernyataan dan pertanyaan

b. Menulis paragraph

${ }^{12}$ Hasan Syahatah, Ta'lim al-Lughah al-'Arabiyyah Baina an-Nazhariyyah wa al-Tathbiq (al-Qahirah: al-Dar al-Mashriyah al-Lubnaniyah, 2002), h. 242. 

c. Menulis surat
d. Menulis karangan pendek
e. Menulis laporan

3. Tingkat lanjut
a. Menulis paragraph
b. Menulis surat
c. Menulis berbagai jenis karangan
d. Menulis laporan. ${ }^{13}$

Diantara tiga tujuan pembelajaran kitabah yang telah penulis paparkan diatas, tujuan yang lebih sesuai dan spesifik menurut penulis berdasarkan tingkatannya yaitu tujuan belajar berdasarkan pandangan Mahmud Kamil An-Naqah.

\section{Prinsip dalam Pembelajaran Maharah al-Kitabah (Keterampilan Menulis)}

Adapun prinsip-prinsip dalam mengajarkan maharatul al-kitabah adalah sebagai berikut:

a. Tema dan ketentuan lainnya harus jelas.

b. Tema dianjurkan berasal dari kehidupan nyata atau pengalaman langsung dari peserta didik, misalnya tentang perayaan, piknik dan sebagainya atau dari pengalaman tidak langsung seperti gambar, film atau hasil dari membaca.

c. Pengajaran insya' harus dikaitkan qowa 'id dan muthala 'ah karena insya' adalah media yang tepat untuk mengimplementasikan qowa'id yang idenya diperoleh dari muthala'ah.

d. Pekerjaan siswa harus dikoreksi, jika tidak, maka peserta didik tidak mengetahui kesalahannya dan dia akan melakukan kesalahan lagi.

e. Untuk mengoreksi kesalahan, sebaiknya diurutkan berdasarkan kepentingannya dan hendaknya dibahas dalam pelajaran khusus. ${ }^{14}$

\section{Teknik Pembelajaran Maharah al-Kitabah (Keterampilan Menulis)}

Teknik pembelajaran adalah cara kongkret yang dipakai saat proses pembelajaran berlangsung. Sedangkan teknik pembelajaran menulis adalah cara mengajarkan (menyajikan

13 Iskandarwassid dan Dadang Sunendar, Strategi Pembelajaran Bahasa (Bandung: UPI \& Rosda Karya, 2008), h. 292-293.

14 Radliyah Zaenuddin, dkk, Metodologi \& Strategi Alternatif Pembelajaran Bahasa Arab, (Yogyakarta: Pustaka Rihlah Group, 2005), hal. 81. 
atau memantapkan) bahan-bahan pelajaran mata pelajaran Bahasa Arab khususnya aspek keterampilan menulis.

Dalam proses pembelajaran maharah al-kitabah terdapat beberapa petunjuk umum, yaitu sebagai berikut:

1. Memperjelas materi yang dipelajari siswa, maksudnya tidak menyuruh siswa menulis sebelum siswa mendengarkannya dengan baik, mampu membedakan pengucapannya dan telah kenal bacaannya.

2. Memberitahukan tujuan pembelajarannya pada siswa.

3. Mulai mengajarkan menulis dengan waktu yang cukup.

4. Asas bertahap, dari yang sederhana berlanjut ke yang sulit. Contoh pelajaran dimulai dengan:

a. Menyalin huruf

b. Menyalin kata

c. Menulis kalimat sederhana

d. Menulis sebagian kalimat yang ada dalam teks atau percakapan

e. Menulis jawaban atas pertanyaan - pertanyaan

f. Imla'

g. Mengarang terarah (misalnya dengan gambar)

h. Mengarang bebas

5. Kebebasan menulis

6. Pembelajaran khat

7. Pembelajaran imla, 15

Adapun prosedur atau tahap dan teknik pengajaran keterampilan menulis (maharah alkitabah) adalah sebagai berikut:

1. Keterampilan Sebelum Menulis Huruf

Pada tahap ini siswa dilatih cara memegang pena dan meletakkan buku di depannya. Demikian juga mereka herus belajar memantapkan cara menggaris, seperti kemiringannya, cara memulai dan cara mengakhiri.

2. Pengajaran Menulis Huruf

Pada tahap ini sebaiknya kita mengikuti langkah-langkah berikut ini:

\footnotetext{
${ }^{15}$ M. Abdul Hamid, dkk, Pembelajaran Bahasa Arab, h. 49-50.
} 
a. Mulai dengan berlatih menulis huruf-huruf secara terpisah sebelum mereka berlatih menulis huruf sambung;

b. Tulislah huruf-huruf tersebut secara tertib sesuai dengan urutan dalam abjad atau dengan mempertimbangkan kemiripan bentuk;

c. Tulislah huruf-huruf sebelum menulis suku kata atau kata

d. Tulislah satu atau dua huruf baru pada setiap pelajaran;

e. Guru memulai menulis contoh tulisan, kemudian para siswa mulai menulis pada buku tulis mereka.

Ketika guru mengajarkan menulis huruf hendaklah diperhatikan hal-hal berikut ini:

a. Guru membimbing para siswa cara memegang pena yang benar serta mengawasi mereka agar terbiasa menulis dengan benar.

b. Guru membimbing para siswa cara duduk yang benar ketika menulis.

c. Memberikan pengarahan dan peringatan akan pentingnya memelihara keserasian di antara huruf-huruf.

d. Guru memperingatkan para siswa akan pentingnya kesatuan jarak antar huruf yang terpisah pada suatu kata. ${ }^{16}$

3. Pengajaran Menyalin (Naskh/Naql)

Setelah para siswa selesai berlatih menulis huruf, baik yang bersambung maupun yang terpisah, sebaiknya mereka diajarkan untuk menyalin pelajaran membaca yang mereka pelajari .

4. Pelajaran Dikte (Imla')

Setelah para siswa dilatih menyalin tulisan untuk jangka waktu yang memadai, mulailah mereka dilatih imla'. Latihan ini dilakukan untuk menguji kemampuan menulis mereka atas apa yang mereka dengar dengan mulanya mereka berlatih dikte tidak berarti mereka berhentik berlatih menyalin. Kedua keterampilan tersebut sebaiknya dikerjakan bersama-sama.

5. Pengajaran Menulis Tersturktur (Insya' Muwajjah)

Setelah para siswa mempelajari menulis huruf-huruf, menyalin, dan dikte, mereka mulai belajar kitabah muqayyadah (menulis terstruktur) yang dinamai juga

16 Aziz Fachrurrozi dan Erta Mahyuddin, Teknik Pembelajaran Bahasa Arab (Bandung: Pustaka Cendekia Utama, 2011), h. 144-145. 
dengan kitabah muwajjahah. Jenis menulis ini diberikan terlebih dahulu sebelum menulis bebas.

6. Pengajaran Menulis Bebas (Insya' Hurr)

Untuk mengajarkan keterampilan menulis bebas, kita bisa mengikuti langkahlangkah berikut:

a. Persiapan menulis bebas

b. Praktik menulis

c. Mengoreksi tulisan bebas. ${ }^{17}$

Pada tingkat Ibtidaiyah pembelajaran maharah al-kitabah dapat direalisasikan melalui mengarang terbimbing (Insya' Muwajjah) kemudian diadakan bimbingan secara bertahap hingga akhirnya berkembang menjadi mengarang bebas (Insya' Hurr).

Bentuk mengarang terbimbing yang paling sederhana adalah menyalin yang kemudian berkembang menjadi upaya memodifikasi kalimat. Misalnya mengganti salah satu unsur kalimat yang (tabdil) atau disebut substitusi, takmilah al-jumlah atau menyempurnakan atau melengkapi kalimat yang belum selesai yang disebut komplesi, tahwil al-fi'il atau mengubah fi'il, mengubah kalimat pasif menjadi aktif, mengubah positif menjadi negative dan lain sebagainya.

Setelah latihan-latihan tersebut, dilanjutkan dengan tahap berikutnya, yaitu menyusun atau menulis kalimat dengan cara membuat kalimat yang tepat untuk menggambarkan sebuah lukisan atau peristiwa atau menceritakan serentetan gambar.

Tahapan-tahapan perubahan ini pun harus menempuh jalan yang tidak pendek, teknik dan latihan yang harus dilalui berupa:

1. Menyingkat bacaan dengan cara menceritakan kembali dalam bentuk tulisan yang menggunakan bahasa siswa sendiri (precis and paraphrase).

2. Menceritakan gambar yang dilihat atau pekerjaan sehari-hari (narration).

3. Menceritakan perbuatan yang biasa dilakukan siswa, seperti aktifitas dikelas, mengendarai angkutan umum dan lainnya (eksposition)

4. Latihan menulis atau mengarang bebas dalam bentuk tulisan tentang masalah yang dikenal oleh siswa.

\footnotetext{
${ }^{17}$ Aziz Fachrurrozi dan Erta Mahyuddin, Teknik Pembelajaran Bahasa Arab, h. 150-153.
} 
Dalam aktivitas pembelajaran menulis, dapat dibagi menjadi tiga ketegori utama, yaitu: menulis terkontrol, menulis terbimbing dan menulis bebas. Menulis terkontrol berada pada tahap pertama sedangkan menulis bebas pada tahap terakhir. ${ }^{18}$

1. Menulis terkontrol adalah aktivitas menulis tahap awal. Kegiatannya masih membutuhkan kontrol atau pengawasan guru, sehingga pada tahap ini guru lebih dominan dibandingkan aktivitas siswa. Berikut ini beberapa yang dapat dilakukan pada menulis terkontrol yang diberikan guru :

a. Kalimat Jigsaw yakni aktivitas meniru teks.

Aktivitas ini mirip dengan meniru teks, hanya saja dilakukan dengan hatihati. Siswa harus mencocokkan setengah dari beberapa kalimat jigsaw dikertas terpisah.

b. Menyalin dan menulis (find and copy).

c. Menyusun kalimat (sentence combining).

d. Menyimpulkan.

2. Menulis terbimbing (muwajjah) yaitu kemampuan menulis menggunakan panduan tentu disertai dengan pemberian stimulus berupa gambar, pertanyaan, kosakata atau kalimat pemandu. Keterampilan menulis terbimbing meliputi:

a. Mengurutkan beberapa kata menjadi kalimat sempurna.

b. Menyusun kalimat dengan sebuah gambar.

c. Menyusun kalimat berdasarkan kosakata.

d. Mengurutkan sebuah kalimat menjadi paragraf.

e. Mendeskripsikan objek atau gambar berdasarkan pertanyaan.

f. Mendeskipsikan sebuah gambar tunggal.

g. Mendeskripsikan sebuah gambar seri.

h. Menyusun sebuah paragraf berdasarkan pertanyaan. ${ }^{19}$

3. Menulis bebas (hurr) yaitu aktivitas menulis dengan menuangkan ide atau gagasan dalam bentuk tulisan.

Demikian paparan sederhana terkait pembelajaran keterampilan menulis dalam bahasa Arab yang meliputi pengertian keterampilan menulis (maharah al-kitabah), tujuan pembelajaran keterampilan menulis (maharah al-kitabah), prinsip-prinsip dalam

\footnotetext{
${ }^{18}$ Furqonul Aziz, Pengajaran Bahasa Komunikatif (Bandung: Remaja Rosda Karya, 1996), h. 131-138.

${ }^{19}$ Moh. Ainin, Evaluasi dalam Pembelajaran Bahasa (Malang : Misykat, 2006), h. 179-180.
} 
pembelajaran keterampilan menulis (maharah al-kitabah) dan teknik pembelajaran keterampilan menulis (maharah al-kitabah).

\section{Simpulan}

Sebagai penutup dalam paparan tulisan ini, disimpulkan bahwa menulis merupakan sebuah kererampilan berbahasa yang sifatnya holistik yang ditunjukan untuk menghasilkan sesuatu yang disebut dengan tulisan. Minimal ada tiga komponen yang tergabung dalam aktivitas menulis yaitu: 1) penguasaan bahasa tulis, meliputi kosa kata, struktur, kalimat, paragraph, ejaan, fragmatik dan sebagainya. 2) Penguasaan isi karangan sesuai dengan topik yang akan ditulis. 3) Penguasaan tentang jenis-jenis tulisan, yaitu bagaimana merangkai isi tulisan dengan menggunakan bahasa tulis sehingga membentuk sebuah komposisi yang diinginkan.

Secara metodologis dalam proses pembelajaran dalam hal ini pembelajaran keterampilan menulis (maharah al-kitabah), maka yang pertama harus dipahami adalah memahami tujuan pembelajaran keterampilan menulis itu sendiri kemudian ditetapkannya sebagai target dalam pembelajaran, begitupun juga pentingnya untuk mengetahui prinsipprinsip pembelajaran keterampilan menulis agar tidak keluar dari lingkup pembahasan dan mengevaluasinya. Yang tak kalah pentingnya adalah mengetahui teknik-teknik pembelajaran khususnya dalam pembelajaran keterampilan menulis, prosedur, tahap dan lainnya agar proses pembelajaran lancar dan mudah sampai pada pembelajar sehingga target yang diharapkan bisa tercapai.

\section{Daftar Rujukan}

Abdul Hamid, M. dkk, Pembelajaran Bahasa Arab, Malang: UIN Malang Press, 2008.

Asyrofi, Syamsuddin, Metodologi Pembelajaran Bahasa Arab, Yogyakarta: Idea Press, 2010. Aziz, Furqonul, Pengajaran Bahasa Komunikatif, Bandung : Remaja Rosda Karya, 1996

Efendi, Anwar, Bahasa dan Sastra dalam Berbagai Prespektif, Jogjakarta: Tiara Wacana, t.th. Fachrurrozi Aziz, dan Erta Mahyuddin, Teknik Pembelajaran Bahasa Arab, Bandung: Pustaka Cendekia Utama, 2011.

Hermawan, Acep, Metodologi Pembelajaran Bahasa Arab, Bandung: Remaja Rosdakarya, 2011.

Iskandarwassid dan Dadang Sunendar, Strategi Pembelajaran Bahasa, Bandung: UPI \& Rosda Karya, 2008. 
Kamil an-Naqah, Mahmud, Ta'lim Lughah al-Arabiyah Lin-Naatiqin bilughatin Ukhra, Makkah: Jamiah Ummul Qura, 1985.

Kunandar, Langkah Mudah Penelitian Tindakan Kelas sebagai Pengembangan Profesi Guru, Jakarta: PT. Raja Grafindo Persada, 2011.

Moh. Ainin, Evaluasi dalam Pembelajaran Bahasa, Malang : Misykat, 2006.

Mustofa, Syaiful, Strategi Pembelajaran Bahasa Arab, Bandung: Remaja Rosdakarya, 2011.

Syahatah, Hasan, Ta'lim al-Lughah al-'Arabiyyah Baina an-Nazhariyyah wa al-Tathbiq, alQahirah: al-Dar al-Mashriyah al-Lubnaniyah, 2002.

Taufik, Pembelajaran Bahasa Arab MI, Surabaya: PMN, 2011.

'Ulyan, Ahmad Fuad Mahmud, al-Maharah al-Lughawiyah, Mahiyatuha wa Turuqu Tadrisuha, Riyadh: Darul Muslim, 1992.

Zaenuddin, Radliyah, dkk, Metodologi \& Strategi Alternatif Pembelajaran Bahasa Arab, Yogyakarta: Pustaka Rihlah Group, 2005. 